\title{
El señalamiento del orden de los apellidos de la persona, en el Anteproyecto de Reforma del Código Civil Peruano. Primeras impresiones
}

\author{
The indication of the order of the person's last name, in the Peruvian Civil Code Reform \\ Project. First impressions
}

César Carranza Álvarez

\begin{abstract}
REFERÊNCIA
ÁLVAREZ, César Carranza. El señalamiento del orden de los apellidos de la persona, en el Anteproyecto de Reforma del Código Civil. Primeras impresiones. Revista da Faculdade de Direito da UFRGS, Porto Alegre, $\mathrm{n}$. 41, p. 38-53, dez. 2019. DOI: 〈https://doi.org/10.22456/0104-6594.99246>.
\end{abstract}

\section{RESUMEN}

En el siguiente texto, el autor analiza el nombre de la persona, con especial atención en la regulación propuesta por el Anteproyecto de Reforma del Código Civil respecto al orden de sus apellidos; valiéndose para ello de las normas vigentes del Código sustantivo, las experiencias del Derecho comparado y los proyectos legislativos del Congreso de la República del Perú sobre el particular.

\section{PALABRAS CLAVE}

Derecho civil. Nombre de la persona. Apellidos de la persona. Anteproyecto de Reforma del Código Civil peruano. Elementos de la personalidad.

\section{ABSTRACT}

In the following text, the autor analyzes the name of the person, with a focus on the regulation proposed by the Civil Code Reform Project regarding the order of their surnames, relying on existing rules of substantive Code; the experiences of comparative law and legislative projects of the Congress of the Republic of Perú on the subject.

\section{KEYWORDS}

Civil law. Name of the person. Surname of the person. Peruvian Civil Code Reform Project. Elements of personality.

\section{SUMARIO}

1. Introducción. 2. Aspectos generales sobre el nombre de la persona. 2.1. Noción y estructura.2.2. Funciones y medidas de aseguramiento. 3. El orden de los apellidos. 3.1. Modelos existentes sobre su conformación. La ruta seguida por el artículo 20 del Código Civil y los reparos a su contenido. 3.2. [Sigue] Consecuencia previsible: los intentos de reforma del artículo 20 del Código Civil. 3.3. ¿Qué nos dice la experiencia extranjera sobre el particular? 4. El nuevo escenario que plantea el artículo 20 del Anteproyecto de Reforma del Código Civil. La norma propuesta y el modelo que adopta. 5. ¿Es aconsejable el cambio? 6. Referencias.

\footnotetext{
* Abogado y Profesor Universitario. Magíster en Derecho de la Empresa por la Pontificia Universidad Católica del Perú y candidato a Doctor en Derecho y CC.PP. Ha realizado estancia docente y de investigación en la Facultad de Derecho de la Universidad de Medellín (Colombia). Escritor. Miembro del Fondo Editorial y Director de la Revista Jurídica del Colegio de Abogados de La Libertad. Registrado en el CTI Vitae del Consejo Nacional de Ciencia, Tecnología e Innovación Tecnológica (Concytec): <https://dina.concytec.gob.pe/appDirectorioCTI/VerDatosInvestigador.do;jsessionid=114a33495721b99603c0b8 546640?id_investigador $=125923>$.
} 


\section{INTRODUÇÃO}

En el presente texto me propongo comentar la propuesta de regulación del orden de los apellidos de la persona, que trae el recientemente publicado Anteproyecto de Reforma del Código Civil peruano elaborado por el Grupo de Trabajo de Revisión y Mejora del referido cuerpo legal, creado mediante Resolución Ministerial N 0300-2016-JUS, presidido por el Profesor Gastón Fernández Cruz, de la Pontificia Universidad Católica del Perú.

Para tal efecto, como marco teórico previo, anotaré algunas consideraciones generales sobre el nombre, para luego derivar en lo que es el objeto de este breve estudio, sirviéndome para ello del contenido actual del artículo 20 del Código Civil, de las críticas que ha merecido; de los proyectos legislativos presentados al Congreso de la República orientados a su modificación, como de algunas sentencias y regulaciones foráneas que desde hace algún tiempo atrás vienen dando cuenta de una tendencia, que parece no tener ya retroceso, de sustraer del Estado la potestad de organizar los apellidos personales para concederla a los padres, en homenaje a su derecho de igualdad y el respeto que merece su vida privada y familiar. En estos términos queda planteada la cuestión a desarrollar.

\section{ASPECTOS GENERALES SOBRE EL NOMBRE DE LA PERSONA}

\subsection{NOCIÓN Y ESTRUCTURA}

Junto a la nacionalidad, el estado civil y el domicilio, el nombre constituye uno de los más importantes elementos de la personalidad, amén de ser considerado un derecho y un deber por el Código Civil nacional (art. 19) ${ }^{1}$. La legislación patria no incorpora definición alguna sobre el nombre. Por tanto, habrá que hurgar en la jurisprudencia y la doctrina para encontrar ahí las ideas que nos permitan tener una noción cabal de aquél.

El Tribunal Constitucional, en reiterada jurisprudencia, ha señalado que el nombre está comprendido dentro de un derecho más amplio, como es el de la identidad, tutelado por la Carta Política en su artículo 2.1. Así, ha declarado que esta norma "expresamente refiere que toda persona tiene derecho a la identidad [...] que comprende [...] el derecho a un nombre conocer a sus padres y conservar sus apellidos-, el relativo a tener una nacionalidad y la

\footnotetext{
${ }^{1}$ Cfr. artículo 6 del Código de los Niños y Adolescentes.
} 
obligación de que el Estado reconozca su personalidad jurídica" (STC Exp. № 00550-2008PA/TC, del 17.9.2010, referencia a STC $\mathrm{N}^{\circ}$ 02432-2005-PHC/TC, Fund. Jur. 4, Caso Espinoza Joffre). En una afirmación más acotada, refiere que constituye "la designación con la cual se individualiza al sujeto y que le permite distinguirse de los demás" (STC Exp. $\mathrm{N}^{\circ}$ 2273-2005-PHC/TC, del 20.4.2006; posición que reitera en la STC Exp. Nº2834-2013PHC/TC, del 25.1.2017), además de indicar su contenido: prenombres y apellidos.

En una antigua sentencia, la Corte Suprema de Justicia señaló que el nombre es "el signo que distingue a las personas en sus relaciones jurídicas y sociales, el que está compuesto por el nombre individual o de pila y por el apellido o nombre de la familia..." (Cas. $\mathrm{N}^{\circ} 1061$ 98-Junín, del 17.11.1998), y más recientemente, en un caso vinculado a un pedido de cambio de nombre, precisó que este "viene a ser la designación mediante el cual se permite identificar a una determinada persona y distinguirla de las demás...” (sic) (Cas. N 835-2016-Ayacucho, del 16.7.2018).

Importante doctrina nacional ha dicho que el nombre constituye "la expresión visible y social mediante la cual se identifica a la persona, por lo que adquiere singular importancia dentro de los derechos de la persona",2, "la representación simbólica del sujeto. Un signo, distintivo o señal gráfica", "la designación con la cual se individualiza al sujeto de derecho, sea éste persona natural, persona jurídica u organización de personas no inscritas" ${ }^{4}$, y "un atributo de su personalidad jurídica, erigiéndose como un requisito indispensable para su vida en relación social" ${ }^{\prime 5}$. Por último, fuera de nuestras fronteras, se encuentran voces que lo definen como "el conjunto de palabras que permite distinguir a una persona jurídica individual de otra", pudiendo considerársele "como una etiqueta colocada sobre cada una de las personas jurídicas individuales", individualizadora del ser humano"7.

\footnotetext{
${ }^{2}$ FERNÁNDEZ SESSAREGO, Carlos. Derecho de las Personas. Exposición de motivos y comentarios al Libro Primero del Código Civil peruano, $5^{\text {ta }}$ edición, Lima: Cultural Cuzco S.A., 1992, p. 80.

${ }^{3}$ VARSI ROSPIGLIOSI, Enrique. Tratado de Derecho de las Personas, Lima: Gaceta Jurídica, 2014, p. 620.

${ }^{4}$ ESPINOZA ESPINOZA, Juan. Comentario al artículo 19 del Código Civil, en: Código Civil comentado por los cien mejores especialistas, AA.VV., tomo I, Lima: Gaceta Jurídica, 2003, p. 183.

${ }^{5}$ HERRERA ARANA, Patricia y TORRES MALDONADO, Marco Andrei. ¿Es viable el cambio de apellidos en el Perú?, en: Gaceta Civil \& Procesal Civil, núm. 52, octubre 2017, p. 194.

${ }^{6}$ MONTOYA OSORIO, Marta Elena y MONTOYA PÉREZ, Guillermo. Las personas en el Derecho Civil, $2^{\mathrm{da}}$ edición, Bogotá: Leyer, 2007, p.76. Puede verse, también, LACALLE NORIEGA, María. La persona como sujeto de derecho, Madrid: Dykinson, 2013, p. 155 y ss.

${ }^{7}$ Peré Raluy, cit. por FERNÁNDEZ PÉREZ, Enrique Antonio. El nombre y los apellidos. Su regulación en derecho español y comparado, Tesis Doctoral, Sevilla, 2014-2015, p. 304; disponible en: $<$ https://idus.us.es/xmlui/bitstream/handle/11441/32106/TESIS\%20definitiva.pdf; sequence=1 >, consultada el 20.9.2019.
} 
Así, puede concebirse al nombre como la denominación que identifica e individualiza a la persona frente a las demás, pero que a su vez permite conocer su procedencia o entronque familiar; el signo que ayuda a saber quién es quién.

Tal se estructura a partir de dos componentes: el prenombre (conocido comúnmente como nombre de pila), elegido libremente por los particulares, y los apellidos, cuyo orden puede quedar al arbitrio de aquellos o ser establecido por el propio legislador, o una combinación de ambos. El Código Civil opta por dicha configuración en el artículo 20, aunque disponiendo una secuencia particular para los apellidos del sujeto, sobre lo cual volveré más adelante.

\subsection{FUNCIONES Y MEDIDAS DE ASEGURAMIENTO}

Con lo avanzado hasta aquí, pueden señalarse las funciones que caben al nombre, siendo básicamente dos: (i) la de identificación del sujeto y (ii) el señalamiento de su entronque familiar. En este sentido, es lógico que el legislador contemple medidas para asegurar que el nombre no sea alterado libremente por la persona, afectando el papel que está llamado a cumplir

Ello explica la prohibición existente en el artículo 29 del Código Civil de cambiar o efectuar adiciones al nombre, salvo que existieran motivos justificados para ello, y siempre mediante autorización judicial, debidamente publicada e inscrita. Como se indicó en el voto en discordia de la Casación No 835-2016-Ayacucho citada, “el análisis del nombre no puede ser limitado únicamente a una visión meramente individualista de la función que este cumple, pues aun cuando es cierto que este constituye primariamente, y, ante todo, un derecho de la persona, no puede perderse de vista que su función identificadora y distintiva no se limita solo al ámbito del individuo, sino que cumple un papel fundamental en la sociedad", por lo que “cualquier modificación que se realice a la designación con la que se identifica a un sujeto (...) afectará proporcionalmente la función individualizadora que ella cumple en la sociedad"

Si bien por mandato del artículo 19 de la norma sustantiva el nombre es un derecho subjetivo de la persona, como correlato se le impone además el deber de mantenerlo y no modificarlo a su solo arbitrio, sino únicamente cuando existieran razones de peso para

\footnotetext{
${ }^{8}$ El texto completo de la sentencia puede leerse en Actualidad Civil, núm. 55, Lima: Instituto Pacífico, enero 2019, pp. 122-132.
} 
proceder a ello, siempre merituadas por el juzgador quien es, finalmente, quien decidirá la procedencia o no de lo peticionado. Por tanto, si bien la inmutabilidad suele ser uno de los caracteres que se pregona del nombre, ella no es absoluta, a la luz del precepto atrás indicado.

Pero además, existen otras disposiciones en el Código orientadas a protegerlo. El derecho de la persona de exigir que se le designe por su nombre, y en caso contrario solicitar el cese del hecho violatorio y la indemnización cuando correspondiera (art. 26); la prohibición de usurpar el nombre de otro y la acción para reclamar el cese del acto y la indemnización a que hubiere lugar (art. 27); la acción concedida a aquel que se perjudique por el cambio o adición de nombre de otro (art. 31), así como la protección que se dispensa al seudónimo, cuando adquiera la importancia del nombre (art. 32).

\section{EL ORDEN DE LOS APELLIDOS}

Menudo problema el de determinar la secuencia de los apellidos de la persona natural. Digo esto porque se suele encontrar diversas posturas respecto a quién debe corresponder su fijación, si al Estado o a los particulares, o a aquél en defecto de acuerdo de los interesados. En las líneas que siguen intentaré mostrar, dentro de los límites que permite el espacio concedido, tal tesitura.

\subsection{MODELOS EXISTENTES SOBRE SU CONFORMACIÓN. LA RUTA SEGUIDA POR EL ARTÍCULO 20 DEL CÓDIGO CIVIL Y LOS REPAROS A SU CONTENIDO}

Aunque reconozco que sobre el particular pueden existir diversas posibilidades regulatorias, que reposan sin más en el temperamento del legislador de turno (y sin dejar de contar las variantes relativas al caso de los hijos adoptivos o niños abandonados, por citar solo algunos), las que señalo a continuación parecen ser las más recurrentes en los conjuntos normativos privados.

Una de ellas consiste en que se reserve al Estado la facultad de fijar el orden de los apellidos de las personas, o lo que es lo mismo, se sustraiga de la iniciativa privada cualquier intento de señalarlo de acuerdo a su conveniencia. Sigue esta línea, por ejemplo, Colombia (Ley 54 de 1989) ${ }^{9}$.

\footnotetext{
${ }^{9}$ Cfr. nota 13.
} 
A dicha opción se opone aquella según la cual se atribuye a los particulares la fijación de los apellidos. Es el caso de Argentina, cuyo Código Civil y Comercial dispone en su artículo 64, primer párrafo, que al hijo matrimonial le corresponde el primer apellido de alguno de los cónyuges, siendo que ante la falta de acuerdo, tal es determinado por sorteo realizado en el Registro del Estado Civil y Capacidad de las Personas. El apellido del otro cónyuge se puede agregar al ya fijado, a pedido de los propios padres, o del interesado con edad suficiente y madurez. Tratándose del hijo extramatrimonial, la regla no es diferente. Solo se autoriza la intervención de un tercero, el Juez, cuando no exista acuerdo entre los padres respecto a dicho orden, que se fijará según el interés superior del niño (art. 64, segundo párrafo, final).

Una variante de la anterior (mixta), por último, es la que resulta de ambas posiciones. En primer lugar, se deja librada a la decisión de los padres la secuencia de los apellidos del hijo, y a falta de acuerdo entre ambos operará lo dispuesto por la ley (es el caso del CC francés, art. 311-21; CC español, art. 109, conc. con la Ley 40/1999, en cuya exposición de motivos se alude, precisamente, a la necesidad de colocar por delante de cualquier previsión legislativa la decisión de los padres de ordenar los apellidos del hijo, y solo en su ausencia se observará lo dispuesto por la ley; y de la Ley $\mathrm{N}^{\circ} 19075$ del Uruguay, cuya regulación difiere según se trate de matrimonio heterosexual u homosexual: en cuanto al primero, la ley dispone un orden específico para los apellidos del hijo, primero el apellido del padre y luego el de la madre, pudiéndose variar ese orden de mediar acuerdo entre ambos; en el segundo caso, el hijo llevará los apellidos de sus padres "en el orden que ellos opten expresamente", en su defecto, se determinará por sorteo al momento de la inscripción, realizado por el Oficial del Estado Civil. Lo mismo aplica para los supuestos de adopción por parte de parejas hetero y homosexuales).

El Código Civil nacional, en su artículo 20, sigue la línea del primer modelo al establecer un orden para los apellidos de la persona, los cuales se configuran de la manera siguiente: el primer apellido del padre seguido del primer apellido de la madre; no obstante un sector de la doctrina nacional señale que el legislador no ha establecido orden alguno, sino simplemente un contenido, lo que posibilitaría en todo caso que se varíe la secuencia que aparece en él (apellido paterno de la madre seguido del paterno del padre) ${ }^{10}$. Pero si esta

\footnotetext{
${ }^{10}$ ESQUIVEL OVIEDO, Juan Carlos. Comentario al artículo 20 del Código Civil, en: Código Civil comentado por los cien mejores especialistas, AA.VV., tomo I, Lima: Gaceta Jurídica, 2003, p. 189. Del mismo modo VARSI ROSPIGLIOSI, op. cit., p. 645, que expresa: «En nuestro caso el artículo 20 del Código dice "al hijo le corresponde el primer apellido del padre y el primero de la madre" pero no dice en este orden. Aunque, luego de
} 
postura fuera cierta, entonces ¿cómo se explican las críticas dirigidas contra dicha norma y la presentación al Congreso de la República de sendos proyectos de ley orientados a modificarla?

En efecto, no han faltado voces en la doctrina científica que consideran que el actual texto del artículo 20 del Código Civil introduce una disposición que violenta el principio derecho de igualdad previsto en el artículo 2.1 de la Carta Constitucional de $1993^{11}$, y como consecuencia de ello, discrimina a la mujer. Estos mismos argumentos, como se verá más adelante, son los que sustentaron los diversos proyectos de ley que han intentado -sin suertesu modificación, y la afectación de la igualdad que se esgrime en la exposición de motivos del nuevo artículo 20 contenido en el Anteproyecto de Reforma del Código Civil.

\section{2 [SIGUE] CONSECUENCIA PREVISIBLE: LOS INTENTOS DE REFORMA DEL ARTÍCULO 20 DEL CÓDIGO CIVIL}

Lo anterior, como no podía ser de otra manera, desembocó meses atrás en la presentación al Congreso de la República de propuestas legislativas orientadas a la reforma del artículo 20 del Código Civil, cuyo propósito era sustraer del Estado la facultad de ordenar los apellidos de la persona para concedérsela a los propios interesados. Ello, mediante soluciones de diverso tipo.

Así, se planteaba que los apellidos sean establecidos de común acuerdo entre los progenitores y a falta de aquél, por medio de su ordenación alfabética (PL 2137/2017-CR) ${ }^{12}$. Si como se vio en el apartado anterior, una de las razones para cuestionar el aludido artículo

\footnotetext{
la modificación del artículo 22 el Código nos dice que en el caso de la adopción del hijo del cónyuge o conviviente este llevará como primer apellido el del padre adoptante y como segundo el de la madre biológica o, el primer apellido del padre biológico y el primer apellido de la madre adoptante, según sea el caso, haciendo norma lo que antes era costumbre». (Negritas del texto).

${ }^{11}$ Así parece sugerirlo ESQUIVEL OVIEDO, Juan Carlos, ibídem. De otro lado, VARSI ROSPIGLIOSI, $o p$. cit., pp. 645-646 señala que "Poner primero el padre desplazando al de la madre a un segundo orden puede sonar inconstitucional, debiera ser más democrático y permitirse la elección. Y es que, la verdad, el segundo apellido es irrelevante y se pierde en la segunda generación. Con base en el criterio de igualdad, el hijo podrá llevar el apellido de ambos o de uno solo o establecer la forma cómo se compondrá el nombre, si primero el apellido del padre y luego el de la madre o viceversa, sobre la base del principio de igualdad de trato entre el apellido paterno y el materno. Debieran ser los padres quienes decidirán el primer apellido del hijo o en su defecto el hijo llegando a la mayoría"; en tanto ESPINOZA ESPINOZA, Juan. Derecho de las Personas, t. II, Lima: Instituto Pacífico, 2019, p. 1136, aunque no emite opinión sobre el particular, parece alinearse en esta posición al hacer eco de la postura de Cristina DE CICO, quien señala que más respetuosa de la autonomía de los cónyuges es posibilitarles la elección de los apellidos de los hijos, pues de lo contrario se estaría ante una afectación de la igualdad de aquéllos, lo cual resulta incluso discriminatorio.

${ }^{12}$ Sobre el particular, remito a CARRANZA ÁLVAREZ, César. ¿Quién debe decidir el orden de los apellidos de las personas?, en: Gaceta Civil \& Procesal Civil, núm. 54, diciembre 2017, pp. 251-252.
} 
20 del Código era la afectación que este producía al derecho de igualdad, al relegar el apellido de la mujer a un segundo plano -a partir de una decisión estatal y no privada-, tal propuesta al final resultaba curiosa, por decir lo menos, toda vez que al recurrirse a la ordenación alfabética, frente al no acuerdo de aquellos, podía llegarse a la misma situación que motivaba el cambio, si es que al final el apellido del padre iniciaba con una letra del alfabeto ubicada por delante de la primera letra del apellido de la mujer.

Un segundo proyecto proponía que al hijo matrimonial le correspondía el primer apellido paterno y el primer apellido materno, en el orden que ambos acordaran, pero sin señalar que ocurría ante la falta de consenso entre ambos. ¿Se aplicaba la secuencia que sugería la norma proyectada, que colocaba en primer lugar el apellido del padre? (PL 2342/2017-CR). Una tercera iniciativa legislativa sugería el mismo temperamento que los dos anteriores, aunque con una solución diferente frente al no acuerdo de los padres. En efecto, se establecía que en este caso le correspondería al funcionario del Registro Civil inscribir al hijo con los apellidos de los padres ordenados alfabéticamente (PL 3918/2018-CR). Y entonces volvemos al mismo punto de partida, del cual se reniega, si es que acontece lo anotado en líneas anteriores.

Por último, se apela al recurso del "interés superior del niño" para resolver el problema que se derivaría si frente a la libertad de elección del orden de los apellidos del hijo, los padres no logran ningún consenso (PL 3994/2018-CR).

Esa variada gama de soluciones legales, vino acompañada de argumentos de todo tipo para justificar el cambio legislativo deseado. Frente a la ya referida violación del derecho a la igualdad y discriminación de la mujer, se adujo que el texto del artículo 20 recortaba la libertad personal (concretamente, de la mujer), que perpetuaba un criterio machista en la conformación del nombre de la persona, que sometía a la mujer a las decisiones del varón, que colisionaba con la tan reclamada -hoy en día- igualdad de género, pero que además desconocía que en el Perú los ingresos de la mujer son inferiores al de los hombres (sic) y que en muchos casos las mujeres son jefas de hogar (sic). A pesar de las consecuencias perniciosas que, según los autores de esos proyectos de ley, se derivaba de tal norma del Código, ninguna de esas propuestas vio finalmente la luz, siendo archivadas y condenadas al olvido, que parecía ser su destino más seguro.

Pero ese intento reformista no puede predicarse como oriundo de esta tierra. Una mirada a decisiones emitidas por las Altas Cortes de algunos países de la región da cuenta de 
un temperamento que parece ya no tener contención alguna. Veamos entonces lo que ha ocurrido.

\section{3 ¿QUÉ NOS DICE LA EXPERIENCIA EXTRANJERA SOBRE EL PARTICULAR?}

Años atrás, la Corte Constitucional de Colombia (Sentencia C-152/94, del 24.3.1994), resolvió una petición de inconstitucionalidad del artículo 1 de la Ley 54 de 1989, por medio de la cual se reformó el artículo 53 del Decreto 1260 de 1970, que establecía que en el Registro de Nacimientos se inscribirán como apellidos del inscrito "el primero del padre, seguido del primero de la madre...”. Por una decisión en mayoría, la Corte se decantó por señalar la constitucionalidad (exequibilidad) de la norma acusada de violar la Constitución de ese país.

En esa oportunidad, la Corte expresó que el nombre no solo constituye un atributo de la personalidad sino también un "procedimiento de identificación", por lo cual a la sociedad le interesa "la existencia de un orden en la manera de fijarlo". Agregó que "[1]a manera como se determina el nombre, obedece a una finalidad social y su regulación corresponde a la ley". En cuanto al cuestionado orden de los apellidos, la Corte se pregunta si dejando ello a la mera decisión de los particulares se avanzaría en el camino hacia la igualdad. La respuesta es negativa. "Evidentemente, no, y ello por una razón elemental -dice el colegiado-: el orden de los apellidos del hijo, nada significa en relación con sus derechos, ni con los de los padres", de suerte que "tiene que existir un orden, y la ley lo ha determinado".

El salvamento de voto opta por una postura contraria. Se lee ahí que "[e]s, justamente, el peligro de tradiciones tan decantadas que generan la creencia de que si así ha sido siempre, no hay motivo para que sea de otro modo. Es la inercia de los productos culturales que sacralizan iniquidades y ciegan a la vez para que se perciban como tales", razón por la cual invertir el orden de los apellidos de la persona, o dejar que tales sean establecidos de común acuerdo por los progenitores, resultaría más armónico con el derecho de igualdad previsto en la Carta Constitucional colombiana ${ }^{13}$.

\footnotetext{
${ }^{13}$ En el momento que este artículo es remitido para su publicación, llega la noticia que la Corte Constitucional de Colombia, mediante la Sentencia C - 159/19, acaba de declarar inexequible (contraria a la Constitución) la
} 
Tiempo después, en México, dos padres quisieron registrar a sus menores hijas, que habían nacido de manera prematura, con el apellido paterno de la madre seguido del apellido paterno del padre, en contra de lo señalado por el artículo 58 del Código Civil para el Distrito Federal. Así, por medio del Amparo en Revisión $N^{\circ}$ 208/2016, de fecha 19.10.2016, la Primera Sala de la Suprema Corte de Justicia de la Nación resolvió la inconstitucionalidad de la referida norma, por las razones que seguidamente sintetizo.

En primer término, considera el alto tribunal que el nombre, en particular la elección de la secuencia de los apellidos, hace parte de un derecho mayor como es el de la intimidad familiar y personal, toda vez que "la elección del nombre de un hijo por sus padres es un momento personal y emocional, razón por la cual queda circunscrito en su esfera privada", de lo que se sigue que "los padres tienen el derecho de nombrar a sus hijos sin injerencias arbitrarias del Estado", que "no solo implica elegir el nombre personal de sus hijos, sino establecer el orden de sus apellidos".

En cuanto a la norma atacada por inconstitucional, declara que "privilegiar el apellido paterno permite mantener concepciones y prácticas discriminatorias en contra de la mujer...inaceptable desde el derecho a la igualdad de género"; "considerar que las mujeres tienen una posición secundaria frente a los padres de sus hijos" fruto de una práctica discriminatoria "en la que se concebía a la mujer como un integrante de la familia del varón, pues era éste quien conservaba la propiedad y el apellido de la familia"; todo lo cual le lleva a concluir que "no se encuentra justificado el limitar el derecho de los padres a decidir el orden de los apellidos de sus hijos, a partir de prejuicios o medidas que pretenden perpetuar la

expresión "seguido del" contenida en el artículo 1 de la Ley 54 de 1989, por medio de la cual los apellidos de la persona se forman primero con el del padre "seguido del" apellido materno.

La Alta Corte fijó el problema jurídico en determinar si esa expresión y su consecuencia implicaba o no un trato discriminatorio entre las mujeres y los hombres, las madres y los padres, y entre las parejas homoparentales y las parejas heterosexuales. A juicio del colegiado, dicha regulación debe ser modificada "porque es el resultado de una vulneración constitución en costumbres que sólo tienen justificación en la tradición" (sic); que "carece de justificación priorizar el apellido del hombre sobre el de la mujer a la hora de inscribir a sus hijos e hijas en el registro civil"; y que además "ese trato dispar se fundamenta en estereotipos y prejuicios del rol disminuido que deberían jugarlas mujeres en la familia, representación a todas luces contraria a la Constitución de 1991 y su visión de igualdad sustantiva". (sic)

Aunque la sentencia anotada resuelve la inexequibilidad de la norma, en ella se declara también que los efectos de la inconstitucionalidad se difieren por el término de dos legislaturas, de modo que el Congreso adecue la legislación a la Constitución y a las convenciones de prohibición de discriminación contra la mujer. Añade la Corte, que si durante ese lapso la legislación no se modificara, deberá entenderse "que el padre y la madre de común acuerdo podrán decidir el orden de asignación de los apellidos de sus hijos, en el acto de inscripción del registro civil. Si no hubiere acuerdo en relación con el orden de los apellidos del hijo por registrar, se definirá por sorteo adelantado por la autoridad competente de asentar el registro civil". (Las cursivas son mías). En razón a ese aplazamiento, mantengo lo anotado respecto a este país, en el apartado 2.1 de este texto. 
situación de superioridad del hombre en las relaciones familiares"; por tanto, dejar a los particulares la potestad asumida por el Estado en cuanto a los apellidos de la persona, además de no afectar la seguridad jurídica constituye la tendencia normativa actual.

Veamos, por último, cuál es la ruta que ahora pretende seguir el legislador nacional en el recientemente publicado Anteproyecto de Reforma.

\section{EL NUEVO ESCENARIO QUE PLANTEA EL ARTÍCULO 20 DEL ANTEPROYECTO DE REFORMA AL CÓDIGO CIVIL. LA NORMA PROPUESTA Y EL MODELO QUE ADOPTA.}

El Grupo de Trabajo de Revisión y Mejora del Código Civil ha propuesto como nuevo texto del artículo 20, el siguiente:

"Artículo 20.- Apellidos del hijo matrimonial

1. Al hijo le corresponde, en ese orden, el primer apellido del padre y el primero de la madre, salvo acuerdo en contrario en cuanto al orden.

2. Todos los hijos de una misma pareja deben llevar los apellidos del primogénito". (Cursivas fuera del texto)

No queda duda que el legislador, a partir de la norma transcrita, se alinea en aquella corriente que he denominado, párrafos atrás, mixta, la cual conjuga la intervención de los particulares y del Estado. ${ }^{14}$ De este modo, el escenario que hoy se plantea parte, en primer lugar, por establecer un orden específico para los apellidos de la persona por medio de la fórmula siguiente: “Al hijo le corresponde, en ese orden, el primer apellido del padre y el primero de la madre”. En segundo término, respecto a esa solución caben dos posibilidades: (i) que los padres decidan libremente y de común acuerdo invertir esa secuencia ("salvo acuerdo en contrario en cuanto al orden”), y (ii) que ante la inexistencia de acuerdo, se acuda al auxilio del legislador para aceptar lo dispuesto por él.

\footnotetext{
${ }^{14}$ La Exposición de Motivos de la norma señala: "El derecho al nombre, que integra el derecho a la identidad personal, permite reconocer a la persona. El Código Civil de 1984 no establece la posibilidad de establecer un orden diverso respecto de los apellidos (primero del padre y de la madre).

La propuesta normativa prevé que puede establecer otro orden de los apellidos, siempre que medie acuerdo de los progenitores. Una vez elegido un orden de los apellidos del primer hijo, todos los demás tendrán ese orden. Se acoge el principio de igualdad, regulado constitucionalmente. Fuente de inspiración de esta propuesta es la Ley 40/1999 de España, sobre nombres y apellidos y su orden, así el artículo 109 del Código Civil de ese país. En Francia, el artículo 311-21 del Code civil”.
} 
La norma así propuesta es interesante. Apela a un orden legal del cual se pregona la afectación a la igualdad entre las personas y, como derivación, la discriminación de la mujer. Pero para morigerar ese impacto negativo, se permite que los padres puedan sin problema alterar esa configuración, para así abonar en pro de aquélla. Pero lo curioso es que ante la ausencia de acuerdo entre los padres, siempre posible como predecible también el surgimiento de conflictos a raíz de ello, aparece otra vez en escena la tan mentada fórmula legislativa. Es decir, un rodeo completo para llegar al mismo punto. Ahora, cabría preguntar si frente a esa libertad concedida a los padres podría oponerse la que corresponde al hijo que no participó en la negociación de la decisión, para permitirle -cuando alcance la mayoría de edad-intentar en la vía judicial un cambio en el orden de sus apellidos, que supondría como derivación el aumento de la carga procesal en un Poder del Estado colapsado por ella y por la permanente carencia de recursos económicos.

Finalmente, en el apartado 2 queda expresamente fijado que "Todos los hijos de una misma pareja deben llevar los apellidos del primogénito".

\section{5 ¿ES ACONSEJABLE EL CAMBIO?}

Tengo ciertas dudas respecto a si algo se gana con el cambio proyectado.

Ellas parten de la aseveración que se suele hacer en cuanto a la vulneración del derecho a la igualdad ${ }^{15}$ de la mujer por obra de la solución adoptada por el legislador, de privilegiar el apellido del padre, o no permitirle intervenir en aquella. No creo que exista una relación entre ambas cuestiones, porque lo mismo podría predicarse de él si es que la fórmula fuera a la inversa. La igualdad, es obvio, debe mirarse en función de ambas partes, no solo de una. Al final, quedamos atrapados en un círculo vicioso francamente insoportable. Similar tesitura acontece con su consecuencia: la discriminación. ¿Cómo se materializa ella respecto a la madre? ¿Su situación dentro de la organización familiar se resquebraja o se altera por esa fórmula legal? ¿Y si el segundo apellido fuera el del padre, se lo discriminaría también?

El derecho a la igualdad que reconoce la Constitución, como la prohibición de discriminar, no guardan conexión con la fórmula legal que ordena los apellidos de la persona.

\footnotetext{
15 "La igualdad -señalan García Belaúnde y Eto- es un principio-derecho que instala a las personas, situadas en idéntica condición, en un plano de equivalencia. Ello involucra una conformidad o identidad por coincidencia de naturaleza, circunstancia, calidad, cantidad o forma, de modo tal que no se establezcan excepciones o privilegios que excluyan a una persona de los derechos que se conceden a otra, en paridad sincrónica o por concurrencia de razones". GARCÍA BELAÚNDE, Domingo y ETO CRUZ, Gerardo. Constitución peruana, Historia y Dogmática, Lima: Adrus Editores, 2016, p. 91.
} 
No niego la existencia de una corriente que tiende hoy en día a mirar el mundo bajo la lupa de la "ideología de género", que incluso está intentando penetrar en el uso del propio idioma español. Tampoco que en muchos espacios de la sociedad peruana la mujer sea tratada en desigualdad de condiciones frente al hombre. Y aquí cabría que nos preguntemos si estas inequidades de algún modo se eliminan o atenúan, respecto a la mujer, con un cambio legislativo como el que se propone.

La situación de la madre al interior del seno familiar, que debe actuar en igualdad de condiciones respecto al padre, no se daña por el solo hecho de que su apellido aparezca en segundo lugar en el del hijo o hijos; más cuando las normas de Derecho Familiar que regulan el vínculo entre aquellos precisamente tiende a preservarla, en armonía con la disposición constitucional indicada y el artículo 4 del Código Civil. Caso contrario, habrá que señalar -lo que no se hace ciertamente- las diversas manifestaciones bajo las cuales se concretiza la denuncia -casi siempre genérica-al artículo 20 de la ley civil.

Si en verdad estamos interesados en una protección plena de la mujer, madre o no, que elimine de la sociedad peruana todas las barreras que le impiden actuar en igualdad de condiciones frente al hombre, entonces ofrezcamos soluciones que tengan un impacto más profundo, de modo que logren desterrar todos esos obstáculos con los que hoy padecen; pero no por medio de fórmulas legales que poco abonan a ese propósito.

De similar modo, no existe una violación a la intimidad de la persona o de su vida familiar, que es otro de los argumentos que se esgrime, como se vio líneas atrás. La formulación del nombre asegura a los padres una amplia libertad para señalar uno de sus componentes: el (os) prenombre (s) del (os) hijo (s) dentro de ese espacio intangible a la mirada ajena, sin mayores restricciones que la de evitar prenombres ridículos, extravagantes, en fin, cualquiera que atente contra la propia dignidad de la persona. Y no se afecta tal derecho porque siendo el apellido de la familia el más importante de los componentes del nombre, el Estado se reserva para sí el establecimiento de su orden. Aún si se pretendiera apelar a la igualdad, esta se asegura al actuar los padres siempre respecto a ese primer elemento.

En síntesis, lo dicho puede quedar de esta forma: Tratándose el nombre de un asunto de especial relevancia para la propia persona, por vincularse a su identificación y a las relaciones que entabla con los demás miembros de la sociedad, amén de imponérsele el deber de cuidarlo y mantenerlo, considero que no debe quedar al arbitrio de los particulares la 
configuración plena de él. De esta forma, la composición del nombre debería mantenerse tal como acontece en la actualidad: librada a la decisión de los padres la elección del (os) prenombre (s), en tanto la fijación del orden de los apellidos al propio Estado, en la secuencia que decida, de modo que se guarde coherencia con la lógica que guía su regulación. La supuesta afectación a los derechos a la igualdad e intimidad personal y familiar, o la discriminación de la mujer, considero no son predicables en esta materia.

El nombre es uno de los elementos de la personalidad más importantes. Interesa a la persona y a la sociedad en su conjunto. Por tanto, pienso que debe corresponderle al Estado intervenir en una parte de su organización.

Con todo, para ir cerrando estas breves líneas, creo que no es posible asumir posiciones definitivas en un tema de tanta discusión como el desarrollado. De ahí que el comentario efectuado se reduzca simplemente a ser una primera impresión respecto al contenido del nuevo artículo 20 que se propone en el Anteproyecto de Reforma del Código Civil, como de la problemática que encierra, y no más que eso. Seguramente los meses por venir darán cuenta de más y mejor doctrina sobre el tema que permitirá replantear estos conceptos por erróneos, o mantenerlos. Tal es el ejercicio de nuestra disciplina.

\section{REFERÊNCIAS}

ANTEPROYECTO DE REFORMA DEL CÓDIGO CIVIL, elaborado por el Grupo de Trabajo de Revisión y Mejora del Código Civil peruano de 1984.

CARRANZA ÁlVAREZ, César. ¿Quién debe decidir el orden de los apellidos de las personas?, en: Gaceta Civil \& Procesal Civil, núm. 54, diciembre 2017.

ESPINOZA ESPINOZA, Juan. Derecho de las Personas, t. II, Lima: Instituto Pacífico, 2019.

ESPINOZA ESPINOZA, Juan. Comentario al artículo 19 del Código Civil, en: Código Civil comentado por los cien mejores especialistas, AA.VV., tomo I, Lima: Gaceta Jurídica, 2003, p. 183.

ESQUIVEL OVIEDO, Juan Carlos. Comentario al artículo 20 del Código Civil, en: Código Civil comentado por los cien mejores especialistas, AA.VV., tomo I, Lima: Gaceta Jurídica, 2003.

FERNÁNDEZ PÉREZ, Enrique Antonio. El nombre y los apellidos. Su regulación en derecho español y comparado, Tesis Doctoral, Sevilla, 2014-2015, p. 304; disponible en: 
$<$ https://idus.us.es/xmlui/bitstream/handle/11441/32106/TESIS\%20definitiva.pdf;sequence=1 $>$, consultada el 20.9.2019.

FERNÁNDEZ SESSAREGO, Carlos. Derecho de las Personas. Exposición de motivos y comentarios al Libro Primero del Código Civil peruano, $5^{\text {ta }}$ edición, Lima: Cultural Cuzco S.A., 1992.

GARCÍA BELAÚNDE, Domingo y ETO CRUZ, Gerardo. Constitución Peruana, Historia y Dogmática, Lima: Adrus Editores, 2016.

HERRERA ARANA, Patricia y TORRES MALDONADO, Marco Andrei. ¿Es viable el cambio de apellidos en el Perú?, en: Gaceta Civil \& Procesal Civil, núm. 52, octubre 2017.

LACALLE NORIEGA, María. La persona como sujeto de derecho, Madrid: Dykinson, 2013.

MONTOYA OSORIO, Marta Elena y MONTOYA PÉREZ, Guillermo. Las personas en el Derecho Civil, $2^{\text {da }}$ edición, Bogotá: Leyer, 2007.

VARSI ROSPIGLIOSI, Enrique. Tratado de Derecho de las Personas, Lima: Gaceta Jurídica, 2014.

\section{DADOS DA PUBLICAÇÃO}

Categoria: artigo de autor convidado.

Recebido em: 18/11/2019.

Aceito em: 19/11/2019. 
ÁLVAREZ, César Carranza. El señalamiento del orden de los apellidos de la persona, en el Anteproyecto de Reforma del Código Civil. Primeras impresiones.Revista da Faculdade de Direito da 